\title{
Ion Complex Formation between Poly(amido amine) Dendrimer HCl Salt and Poly(L-glutamic acid) Sodium Salt
}

\author{
Kaname Tsutsumiuchi, Keigo AoI, and Masahiko OKada ${ }^{\dagger}$ \\ Department of Applied Molecular Biosciences, Graduate School of Bioagricultural Sciences, \\ Nagoya University, Chikusa-ku, Nagoya 464-8601, Japan
}

(Received June 14, 1999)

\begin{abstract}
Formation of ion complexes between poly(amido amine) (PAMAM) dendrimer HCl salt (1) (ethylenediamine core, generation $G=3.0$ and 5.0$)$ and poly(L-glutamic acid) sodium salt $(\mathbf{2})\left(M_{w}, 1.3 \times 10^{4}, 1.5 \times 10^{4}\right.$, and $8.9 \times$ $\left.10^{4}\right)$ in water and phosphate buffers $(\mathrm{pH} 6.0,6.9$, and 7.9 ) was investigated by $\mathrm{pH}$, turbidity, and viscosity measurements and electrophoresis analysis. In $\mathrm{pH}$ and turbidity measurements in water, the highest turbidity and neutralization were observed around a $1: 1$ charge ratio, demonstrating that not only primary amines on the surface but also internal tertiary amines of 1 participate in the ion complex formation. When lower molecular weight $2\left(M_{w}, 1.3 \times 10^{4}\right.$ and $\left.1.5 \times 10^{4}\right)$ were used for complexation in water and phosphate buffers, mixtures of $\mathbf{1}$ and $\mathbf{2}$ did not become turbid except around the point of neutralization in water. In electrophoresis, the non-turbid mixtures of $\mathbf{1}(G=5.0)$ and $\mathbf{2}\left(M_{w}, 1.5 \times 10^{4}\right)$ showed a characteristic broad band, meaning ion complex formation. Viscosity of the aqueous solutions of a mixture of 1 and $2\left(M_{w}\right.$, $\left.1.5 \times 10^{4}\right)$ was lower than that of $2\left(M_{w}, 1.5 \times 10^{4}\right)$. The conformation of 2 in the complex was proved to be a random coil by circular dichroism (CD) analysis. These results were interpreted in terms of water-soluble ion complex formation due to the globular shape and molecular structure of 1.
\end{abstract}

KEY WORDS Dendrimer / Polypeptide / Polyelectrolyte / Electrostatic Interaction / Macromolecular Association / Water-Soluble Ion Complex /

Dendrimers are highly symmetric branched macromolecules with a branch point at each repeat unit. ${ }^{1-3}$ Recent progress in dendrimer chemistry has made it possible not only to precisely control the size and shape of dendrimers but also to impart important functions not possible before. ${ }^{4}$ One diverse application is complex formation in internal and external regions. Despite many papers concerning self-assemblies and interactions of dendrimers with various compounds, ${ }^{5,6}$ there have been few papers on the formation of ion complexes between dendrimers and linear synthetic polymers. ${ }^{7-9}$ Usually, interactions between linear polycations and linear polyanions are very strong and highly ion-paired amorphous complexes precipitate (cooperative interaction)..$^{10}$ Tsuchida et al . observed a water-soluble complex composed of polycation having cationic charges on the backbone chain and pendant type polyanion. ${ }^{11}$ Some dendrimers have primary and tertiary amine moieties in surface layers and branching points, respectively, and their salts can be thought of as new spherical polycations with cationic charges on the periphery and internal skeleton. The globular structure is expected to suppresses crosslinking. Some water-soluble ion complexes composed of polyelectrolyte and micelle have been reported. ${ }^{12,13}$ Therefore, it is feasible that dendrimers form a new class of water-soluble ion complexes.

Ion complexes with polyelectrolytes have been applied as medical materials (bio-compatibilizer ${ }^{14}$ and microcapsule ${ }^{15}$ ) and are of significant interest because of potential application in gene and drug delivery systems. ${ }^{16-18}$ Poly (amido amine) (PAMAM) dendrimer binds to plasmid DNA by electrostatic interaction and enhances DNA transfer and expression in a variety of mammalian cell lines. ${ }^{19,20}$ The lack of toxicity, high transfection effi-

\footnotetext{
${ }^{\dagger}$ To whom correspondence should be addressed.
}

ciency, and stability of DNA/dendrimer complexes suggest that this transfection method may be useful in in vivo application. Dendrimers are possible drugcontainers in drug delivery systems owing to encapsulation ability. ${ }^{21-29}$ We synthesized diverse glycopeptideconjugated macromolecules with molecular recognition ability, based on the ring-opening polymerization of sugar-substituted $\alpha$-amino acid $N$-carboxyanhydrides (glycoNCAs) ${ }^{29-36}$ Syntheses of several carbohydrate-poly (glutamic acid) conjugates have been reported recently. ${ }^{37-40}$ There is the possibility that new biofunctional materials are produced from complexes between dendrimers and sugar-polypeptide conjugates. Therefore we selected the anionic polypeptide, poly(L-glutamic acid), as a partner polyelectrolyte which complexes with dendrimer as polycation having cationic charges on the backbone chain. This study investigates the formation of ion complexes between PAMAM dendrimer $\mathrm{HCl}$ salt (1) (ethylenediamine core, generation $G=3.0$ and 5.0) and poly(L-glutamic acid) sodium salt $(2)\left(M_{w}, 1.3 \times 10^{4}, 1.5 \times\right.$ $10^{4}$, and $8.9 \times 10^{4}$ ) in water and phosphate buffers. Evaluation of the complexation was carried out by $\mathrm{pH}$, turbidity, and viscosity measurements and electrophoresis. Conformation of 2 in the complex was analyzed by circular dichroism (CD) spectroscopy.

\section{EXPERIMENTAL}

\section{Materials}

PAMAM dendrimer (ethylenediamine core, $G=3.0$ ) was purchased from Aldrich Chemical Co. PAMAM dendrimer (ethylenediamine core, $G=5.0$ ) was prepared from PAMAM dendrimer (ethylenediamine core; $G=$ 4.0) (Aldrich Chemical Co.) by the stepwise method of Tomalia et al. ${ }^{41}$ Calculated molecular weights of PAMAM dendrimers $(G=3.0$ and 5.0) in consideration 
of the branching ratio (ratio of tertiary amine structure to all branching points obtained by ${ }^{13} \mathrm{C}$ NMR measurements in $\mathrm{D}_{2} \mathrm{O}$ at $27^{\circ} \mathrm{C}$ ) were $6.67 \times 10^{3}$ and $2.81 \times 10^{4}$, respectively. For both samples, $M_{w} / M_{n}$ estimated by size exclusion chromatography was 1.01 (column, superdex $75 \mathrm{HR}$ 10/30 (Pharmacia Biotech); eluent, $50 \mathrm{mmol} \mathrm{L}^{-1}$ $\mathrm{Na}_{2} \mathrm{HPO}_{4}$ aq. $+\mathrm{NaOH}(\mathrm{pH} 11)$; temp., $27^{\circ} \mathrm{C}$; flow rate, $0.50 \mathrm{~mL} \mathrm{~min}{ }^{-1}$; standard, globular proteins (Pharmacia Biotech)). PAMAM dendrimer $\mathrm{HCl}$ salts (1) $(G=3.0$ and 5.0) all of whose primary and tertiary amines were transformed to $\mathrm{HCl}$ salts were prepared by treatment of PAMAM dendrimers (ethylenediamine core, $G=3.0$ and 5.0) with dilute hydrochloric acid and reprecipitation in diethyl ether from methanol. Poly(L-glutamic acid) sodium salts $(2)\left(M_{w}, 1.3 \times 10^{4}, 1.5 \times 10^{4}\right.$, and $8.9 \times 10^{4}$; $M_{w} / M_{n}, 1.20,1.20$, and 1.26 , respectively) were purchased from Sigma Chemical Co. and found to contain $12-14 \%$ ethyl glutamate residues by ${ }^{1} \mathrm{H}$ NMR measurement. Milli-Q water was used throughout this work.

\section{$p H$ and Turbidity Measurements of Mixtures of PAMAM}

Dendrimer HCl Salt (1) and Poly(L-glutamic acid) Sodium Salt (2) in Water

$\mathrm{pH}$ measurement was carried out using a Toa $\mathrm{pH}$ meter model HM-5A. Turbidity, recorded as absorbance, was obtained at $500 \mathrm{~nm}$ by a Jasco Ubest-30 UV/vis spectrophotometer. A $0.1-0.3 \mathrm{~mL}$ aqueous solution of 1 (conc., $1.5 \mathrm{~g} \mathrm{~L}^{-1}$; [cation], $0.010 \mathrm{~mol} \mathrm{~L}^{-1}$ ) was added dropwise to a $20 \mathrm{~mL}$ aqueous solution of 2 (conc., $0.15 \mathrm{~g}$ $\mathrm{L}^{-1}$; [anion], $8.5 \times 10^{-4} \mathrm{~mol} \mathrm{~L}^{-1}$ ) and the mixture was stirred for $20 \mathrm{~min}$. After $\mathrm{pH}$ measurement of the mixture, an aliquot was transferred to a $1-\mathrm{cm}$ path length quartz cell for turbidity evaluation and returned to the vessel prior to further addition of dendrimer solution. This procedure was repeated until the total volume of the solution of 1 reached $3.7 \mathrm{~mL}$. Next, a $1.0-5.0 \mathrm{~mL}$ aqueous solution of 2 (conc., $0.15 \mathrm{~g} \mathrm{~L}^{-1}$; [anion], $8.5 \times 10^{-4} \mathrm{~mol}$ $\mathrm{L}^{-1}$ ) was poured into the mixture ([cation]/[anion] $=2.2$ ), followed by the same procedure. This procedure was repeated until the total volume of the solution of 2 reached $70 \mathrm{~mL}$. All experiments were done at $27^{\circ} \mathrm{C}$.

Turbidity Measurement of Mixtures of PAMAM Dendrimer HCl Salt (1) and Poly(L-glutamic acid) Sodium Salt (2) in Phosphate Buffers

Turbidity measurement in $0.10 \mathrm{~mol} \mathrm{~L}^{-1}$ phosphate buffers ( $\mathrm{pH} 6.0,6.9$, and 7.9) was carried out for complexation between $1(G=3.0)$ and $2\left(M_{w}, 1.5 \times 10^{4}\right)$ as follows. First, a $0.20 \mathrm{~mL}$ phosphate buffer solution of 2 (conc., $0.15 \mathrm{~g} \mathrm{~L}^{-1}$; [anion], $8.5 \times 10^{-4} \mathrm{~mol} \mathrm{~L}^{-1}$ ) was put into each well of a 96 well-plate. Then, a $0-34 \mu \mathrm{L}$ phosphate buffer solution of 1 (conc., $1.5 \mathrm{~g} \mathrm{~L}^{-1}$; [cation], $0.010 \mathrm{~mol} \mathrm{~L}^{-1}$ ) was added to the phosphate buffer solution of 2 ([cation]/[anion] $=0--2.0$ ). Absorbance at 500 $\mathrm{nm}$ was measured at intervals for $24 \mathrm{~h}$ after mixing by using a microplate spectrophotometer system SPECTRAmax 250 from Molecular Devices. For comparison, turbidity measurement in water was carried out by the same manner with that in phosphate buffers.

\section{Electrophoresis}

In the case of complexation in water, $10 \mu \mathrm{L}$ mixtures of aqueous solution of 1 (conc., $1.5 \mathrm{~g} \mathrm{~L}^{-1}$; [cation], 0.010 mol L $\mathrm{L}^{-1}$ ) and aqueous solution of 2 (conc., $0.15 \mathrm{~g} \mathrm{~L}^{-1}$; [anion], $\left.8.5 \times 10^{-4} \mathrm{~mol} \mathrm{~L}^{-1}\right)$ containing $10 \%(\mathrm{v} / \mathrm{v})$ glycerol were added into slots of polyacrylamide gel in 0.10 mol L $\mathrm{L}^{-1}$ phosphate buffer ( $\mathrm{pH}$ 6.9). In the case of complexation in $0.10 \mathrm{~mol} \mathrm{~L}^{-1}$ phosphate buffers ( $\mathrm{pH}$ 6.0, 6.9, and 7.9), $10 \mu \mathrm{L}$ mixtures of a phosphate buffer solution of 1 (conc., $1.5 \mathrm{~g} \mathrm{~L}^{-1}$; [cation], $0.010 \mathrm{~mol} \mathrm{~L}^{-1}$ ) and a phosphate buffer solution of 2 (conc., $0.15 \mathrm{~g} \mathrm{~L}^{-1}$; [anion], $\left.8.5 \times 10^{-4} \mathrm{~mol} \mathrm{~L}^{-1}\right)$ containing $10 \%(\mathrm{v} / \mathrm{v})$ glycerol were placed in slots of polyacrylamide gel in the corresponding buffers. Electrophoresis was performed in the constant voltage operation mode $(50 \mathrm{~V})$ until xylene cyanol $\mathrm{FF}$ as a marker migrated by $1.0 \mathrm{~cm}$. Post electrophoresis samples were stained and fixed by $0.25 \%(\mathrm{w} / \mathrm{v})$ coomassie brilliant blue R-250 aqueous solution containing $45 \%$ $(\mathrm{v} / \mathrm{v})$ methanol and $9.2 \%(\mathrm{v} / \mathrm{v})$ acetic acid.

\section{Viscosity and Circular Dichroism Measurements}

The hydrodynamic properties of complexes and polyelectrolytes were measured by an Ubbelohde viscometer at $27^{\circ} \mathrm{C}$. All viscosity measurements of solutions of $\mathbf{1}(G$ $=5.0)+2\left(M_{w}, 1.5 \times 10^{4}\right)($ cation] $/[$ anion] $=0.50$ and 2.0$)$ were carried out at $1 \mathrm{~h}$ after the preparation of the solutions. CD analysis was performed by a Jasco J-720 spectropolarimeter at $25^{\circ} \mathrm{C}$. Sample solutions were adjusted to [cation]/[anion] $=0.50$ and 2.0 by adding an aqueous solution of 1 ( $G=5.0$ ) (conc., $1.5 \mathrm{~g} \mathrm{~L}^{-1}$; [cation], 0.010 mol $\left.\mathrm{L}^{-1}\right)$ to an aqueous solution of $2\left(M_{w}, 1.5 \times 10^{4}\right)$ (conc., $0.15 \mathrm{~g} \mathrm{~L}^{-1}$; [anion], $8.5 \times 10^{-4} \mathrm{~mol} \mathrm{~L}^{-1}$ ).

\section{RESULTS AND DISCUSSION}

\section{pH and Turbidity Measurements of Mixtures of PAMAM Dendrimer HCl Salt (1) and Poly(L-glutamic acid) So- dium Salt (2) in Water}

The results of the $\mathrm{pH}$ and turbidity measurements for $1(G=3.0)+2\left(M_{w}, 1.3 \times 10^{4}\right), 1(G=5.0)+2\left(M_{w}, 1.3 \times\right.$ $\left.10^{4}\right), 1(G=3.0)+2\left(M_{w}, 8.9 \times 10^{4}\right)$, and $1(G=5.0)+2$ $\left(M_{w}, 8.9 \times 10^{4}\right)$ are shown in Figures $1 \mathrm{a}, 1 \mathrm{~b}, 1 \mathrm{c}$, and $1 \mathrm{~d}$, respectively.

When an aqueous solution of $\mathbf{1}(G=3.0)$ was added in small portions to an aqueous solution of $2\left(M_{w}, 1.3 \times 10^{4}\right)$ (Figure 1a, left side), the highest turbidity appeared around the point of neutralization and absorbance was very low in [cation]/[anion] $<0.8$ and [cation]/[anion] $>1.4$. This coacervation may be attributed to shrinkage of oppositely charged polyelectrolytes due to neutralization. The highest absorbance and neutralization around a 1 : 1 charge ratio demonstrated that the internal amine moieties as well as those on the surface of 1 participated in the formation of the ion complex. When an aqueous solution of $2\left(M_{w}, 1.3 \times 10^{4}\right)$ was added to the mixture of $1(G=3.0)$ and $2\left(M_{w}, 1.3 \times 10^{4}\right)([$ cation]/[anion]=2.2) (Figure 1a, right side), the highest turbidity was observed around the point of neutralization. Interestingly, the absorbance was about 2 times that in adding a solution of $1(G=3.0)$ to a solution of 2 . These results suggest that a water-soluble ion complex is formed in [cation]/[anion] $>1.4$ and that the association between the complex and $2\left(M_{w}, 1.3 \times 10^{4}\right)$ results in the higher turbidity in the consecutive addition of $2\left(M_{w}, 1.3 \times 10^{4}\right)$. Similar plots were obtained in the case of $1(G=5.0)+2$ $\left(M_{w}, 1.3 \times 10^{4}\right)$ as shown in Figure $1 \mathrm{~b}$. 

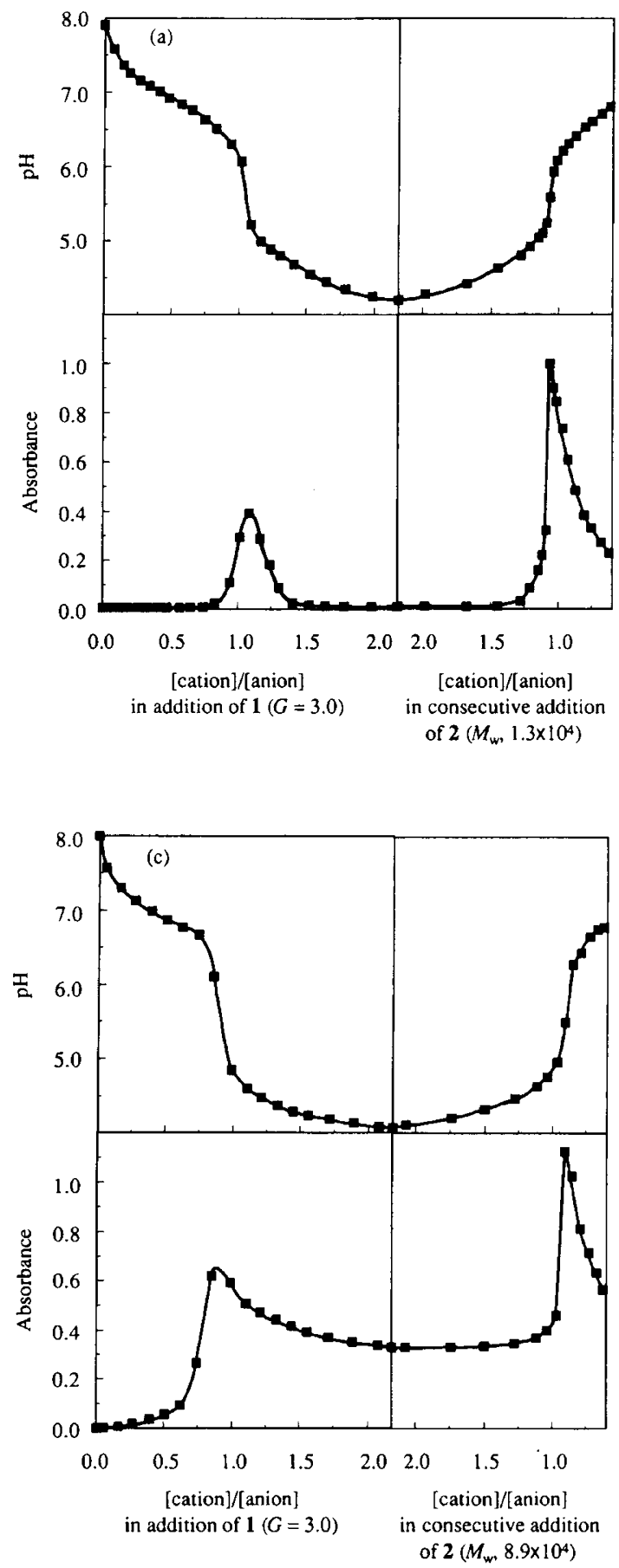
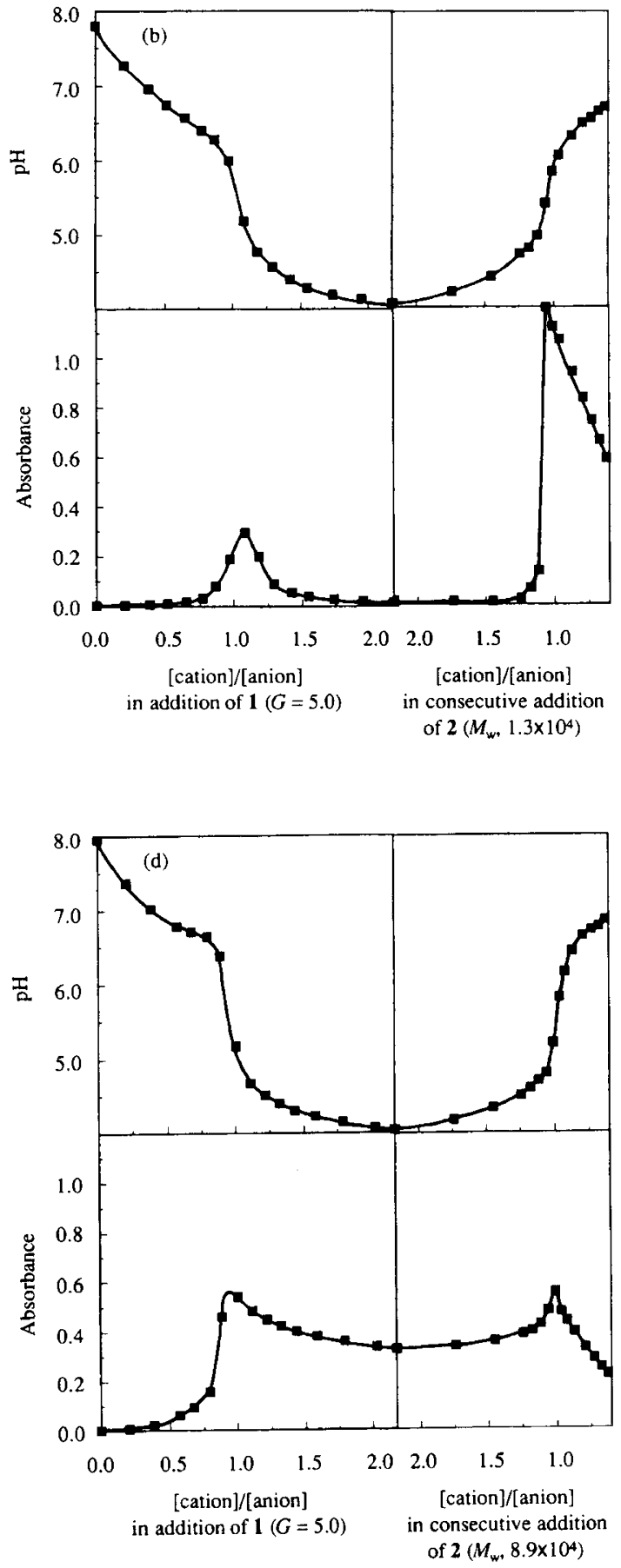

Figure 1. $\mathrm{pH}$ and absorbance of mixtures of 1 and 2. In addition of 1 (left side in graph), an aqueous solution of 1 ([cation], 0.010 mol $\mathrm{L}^{-1}$ ) was added dropwise to a $20 \mathrm{~mL}$ aqueous solution of 2 ([anion], $8.5 \times 10^{-4} \mathrm{~mol} \mathrm{~L}^{-1}$ ). In consecutive addition of 2 (right side), an aqueous solution of 2 ([anion], $8.5 \times 10^{-4} \mathrm{~mol} \mathrm{~L}{ }^{-1}$ ) was added to the final mixture. Each measurement was carried out at 20 min after adding. (a) 1 ( $G=$ $3.0)+2\left(M_{w}, 1.3 \times 10^{4}\right)$, (b) $1(G=5.0)+2\left(M_{w}, 1.3 \times 10^{4}\right),(\mathrm{c}) \mathbf{1}(G=3.0)+2\left(M_{w}, 8.9 \times 10^{4}\right),(\mathrm{d}) 1(G=5.0)+\mathbf{2}\left(M_{w}, 8.9 \times 10^{4}\right)$. Temperature, $27^{\circ} \mathrm{C}$; wavelength, $500 \mathrm{~nm}$.

When higher molecular weight $2\left(M_{w}, 8.9 \times 10^{4}\right)$ was used (Figures 1c and 1d), absorbance was higher than that observed for lower molecular weight $2\left(M_{w}, 1.3 \times\right.$ $10^{4}$ ) and the mixture remained turbid even in [cation]/ [anion] $>1.4$. The different phenomena depending on the molecular weight of $\mathbf{2}$ may be interpreted in terms of electrostatic crosslinking. The numbers of cation charge per molecule of $1(G=3.0)$ and $1(G=5.0)$ were estimated to be 60 and 254 in consideration of the branching ratio, respectively. The average numbers of anion charge per $2\left(M_{w}, 1.3 \times 10^{4}\right)$ and $2\left(M_{w}, 8.9 \times 10^{4}\right)$ molecules were calculated to be 73 and 501 considering the content of ethyl ester residue. Therefore, when $2\left(M_{w}, 8.9 \times 10^{4}\right)$ is used, the electrostatic crosslinking between the complexes is more likely to take place, because 2 has more charges than $1(G=3.0)$ and $1(G=5.0)$, although a shorter single chain of $2\left(M_{w}, 1.3 \times 10^{4}\right)$ might be almost entrapped on and inside one molecule of 1 . Slight turbidity in [cation]/[anion] $<0.8$ in adding a solution of 1 to a solution of $2\left(M_{w}, 8.9 \times 10^{4}\right)$ supports complex formation 


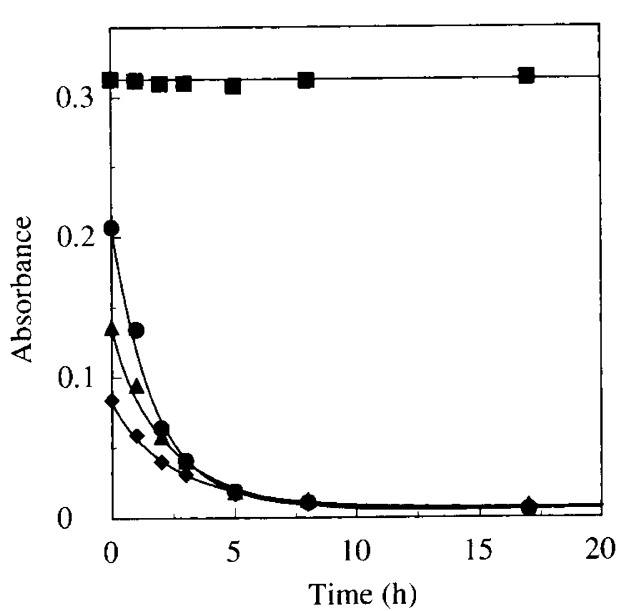

Figure 2. Time dependency of absorbance of mixtures of $\mathbf{1}(G=$ 5.0) and $2\left(M_{w}, 1.5 \times 10^{4}\right)$ ([cation]/[anion] $\left.=1.0\right)$ in various solvents (呙, water ;, $0.10 \mathrm{~mol} \mathrm{~L}^{-1}$ phosphate buffer $(\mathrm{pH} 6.0) ; \mathbf{\Delta}, 0.10$ mol L ${ }^{-1}$ phosphate buffer $(\mathrm{pH} 6.9) ; \diamond, 0.10 \mathrm{~mol} \mathrm{~L}^{-1}$ phosphate buffer ( $\mathrm{pH} 7.9)$ ). Temperature, $27^{\circ} \mathrm{C}$; wavelength, $500 \mathrm{~nm}$.

in this region and a water-soluble complex may form in [cation]/[anion] $<0.8$ on adding a solution of 1 to a solution of $2\left(M_{w}, 1.3 \times 10^{4}\right)$.

Turbidity Measurement of Mixtures of PAMAM Dendrimer HCl Salt (1) and Poly (L-glutamic acid) Sodium Salt (2) in Phosphate Buffers

The ion complex formation between 1 and $\mathbf{2}$ was examined in three different phosphate buffers to investigate the complexation under pH-controlled conditions. First, turbidity evaluation of the phosphate buffer solutions of $1(G=5.0)+\mathbf{2}\left(M_{w}, 1.5 \times 10^{4}\right)([$ cation] $/[$ anion] $=1.0)$ was carried out by a microplate spectrophotometer. Time dependency of the absorbance at $500 \mathrm{~nm}$ is shown in Figure 2. The absorbance in these phosphate buffer solutions decreased with time, although turbidity in water did not change at all.

To confirm the disappearance of turbidity in phosphate buffers, turbidity measurement was performed at various charge ratios. The results at $24 \mathrm{~h}$ after preparing the mixtures are shown in Figure 3. Turbidity in these buffer solutions was quite low in the range of $0 \leqq$ [cation]/ [anion] $\leqq 2.0$, whereas the turbidity in water clearly increased around [cation]/[anion] $=1.0$.

Probably the ion complex between $\mathbf{1}$ and $\mathbf{2}$ became more soluble at high ionic strength, since the screening effect of microsalts reduced the electrostatic interaction. ${ }^{10}$ In general, a complex between a weak polyacid and weak polybase is formed as a coacervate only in the neutral $\mathrm{pH}$ region and not formed at higher and lower $\mathrm{pH}$, because the degree of dissociation of either the weak polyacid or the weak polybase is relatively low. ${ }^{10}$ In the present system, no turbidity of the mixtures was visible at $\mathrm{pH} 6.0,6.9$, and 7.9. This seems due to the unique structure of 1 having cationic charges not only on the surface layer but also on the globular dendrimer skeleton.

\section{Electrophoresis}

In turbidity measurement, we thought that a watersoluble complex is formed when no turbidity is observed.

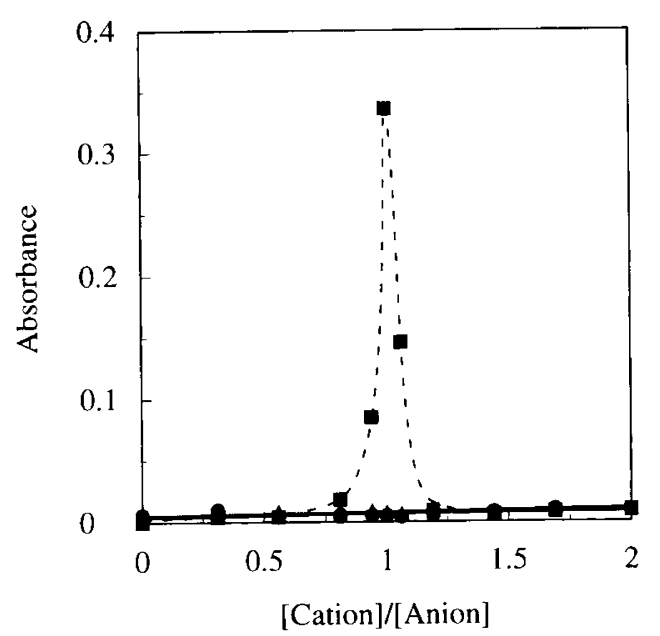

Figure 3. Absorbance of mixtures of $\mathbf{1}(G=5.0)$ and $\mathbf{2}\left(\boldsymbol{M}_{w}, 1.5 \times\right.$ $\left.10^{4}\right)$ at $24 \mathrm{~h}$ after the preparation in various solvents $(\square$, water ; $0.10 \mathrm{~mol} \mathrm{~L}^{-1}$ phosphate buffer $(\mathrm{pH} 6.0) ; \mathbf{\Lambda}, 0.10 \mathrm{~mol} \mathrm{~L}^{-1}$ phosphate buffer $(\mathrm{pH} 6.9) ; \diamond, 0.10 \mathrm{~mol} \mathrm{~L}^{-1}$ phosphate buffer $(\mathrm{pH} 7.9)$ ). Temperature, $27^{\circ} \mathrm{C}$; wavelength, $500 \mathrm{~nm}$.

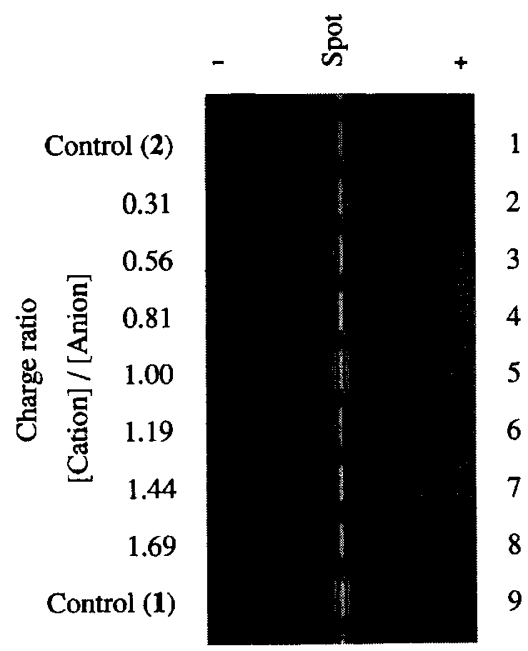

Figure 4. Electrophoresis of mixtures of $1(G=5.0)$ and $2\left(M_{w}, 1.5\right.$ $\left.\times 10^{4}\right)$ in water at various charge ratios. Lane 1,2 ; lanes $2-8$, mixtures of 1 and 2 at the indicated charge ratios ; lane $9 ; 1$. (polyacrylamide gel ; $0.10 \mathrm{~mol} \mathrm{~L}^{-1}$ phosphate buffer; $\mathrm{pH} 6.9$; stained with coomassie brilliant blue R-250).

Therefore, the complexation between $1(G=5.0)$ and 2 $\left(M_{w}, 1.3 \times 10^{4}\right)$ was analyzed by electrophoresis with a polyacrylamide gel. Figure 4 shows the result of electrophoresis in the complexation between $1(G=5.0)$ and 2 $\left(M_{w}, 1.3 \times 10^{4}\right)$ in water.

$1(G=5.0)$ and $2\left(M_{w}, 1.5 \times 10^{4}\right)$ as controls migrated toward the cathode and anode (lanes 9 and 1), respectively. These two lanes indicate that 1 was stained well but 2 was hardly stained by coomassie brilliant blue R250. Visible bands in this electrophoresis may thus represent the existence of 1 . In lanes $2-8$, broad bands were observed from slots toward cathode side (lanes 2-4) and both sides (lanes $6-8$ ). 2 thus changes the mobility of $\mathbf{1}$ in the gel. Turbidity measurement and electrophoresis analysis indicated that a water-soluble ion complex was generated between 1 and 2 . We recognized the change of the deepest-stained position with increasing charge ratio. This indicates that the ion complex forms 


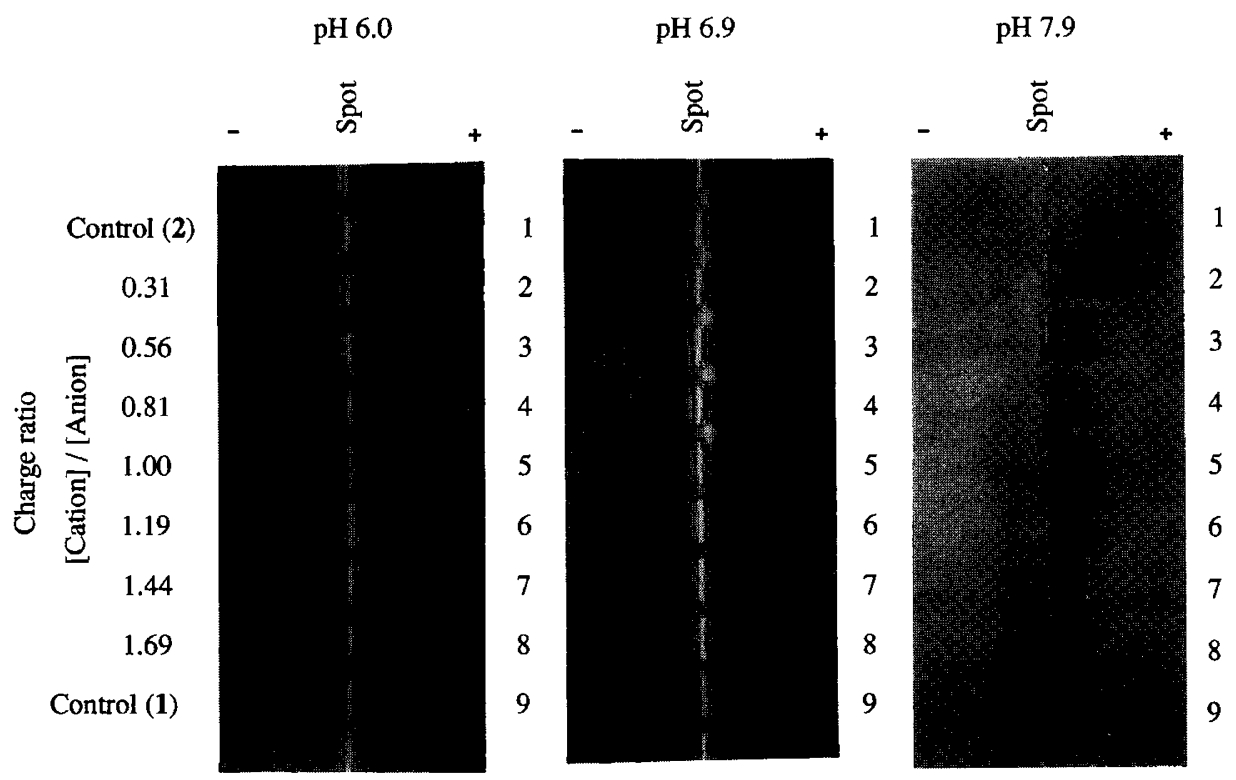

Figure 5. Electrophoresis of mixtures of $1(G=5.0)$ and $2\left(M_{w}, 1.5 \times 10^{4}\right)$ in 0.10 mol L ${ }^{1}$ phosphate buffers (pH 6.0, 6.9, and 7.9) at various charge ratios. Lane 1,2 ; lanes $2-8$, mixtures of 1 and 2 at the indicated charge ratios; lane 9 ; 1 . (polyacrylamide gel ; 0.10 mol $\mathrm{L}^{-1}$ phosphate buffer ; pH 6.0,6.9, and 7.9, respectively ; stained with coomassie brilliant blue R-250).

at various molar ratios in contrast to "all or none type" complex formation mechanism. ${ }^{10}$ The slight staining at the point of neutralization (lane 5 , [cation]/[anion] $=1.0$ ) is probably due to the phase-separated complex which could not permeate the cross-linked polyacrylamide gel.

As shown in Figure 5, the electrophoresis analysis of the mixtures in three different phosphate buffers $(\mathrm{pH}$ $6.0,6.9$, and 7.9) demonstrate the formation of the watersoluble ion complex.

Though lanes 5 and 6 in $\mathrm{pH} 6.0$ were hardly stained, free 1 was not observed. Considering the results of $\mathrm{pH}$ measurement in Figure 1, probably the complex did not migrate into polyacrylamide gel owing to the isoelectric point around $\mathrm{pH} 6.0$. We recognized that in $\mathrm{pH} 6.0,6.9$, and 7.9 free 1 which did not participate in the complex formation was found at [cation]/[anion] $\geqq 1.44,0.81$, and 0.56 , respectively. This reflects the aforementioned $\mathrm{pH}$ responsive character of ion complexes between a weak polyacid and weak polybase. Thus, with increasing $\mathrm{pH}$ the degree of dissociation of $\mathbf{1}$ decreases and the interpolymer association becomes weak.

\section{Viscosity and Circular Dichroism Measurements}

Formation of a water-soluble ion complex was also supported by the viscosity measurement. Figure 6 shows viscosity of aqueous solutions of $2\left(M_{w}, 1.5 \times 10^{4}\right)$ and the mixtures of $\mathbf{1}(G=5.0)$ and $\mathbf{2}\left(M_{w}, 1.5 \times 10^{4}\right)$ ([cation]/ [anion] $=0.50$ and 2.0 ).

The $\mathrm{X}$ axis in Figure 6 represents the concentration of 2. The total concentrations of $\mathbf{1}$ and $\mathbf{2}$ in the mixture solutions ([cation]/[anion] $=0.50$ and 2.0 ) were 1.4 and 2.8 times higher than that of 2 , respectively. Nevertheless, the viscosities of the mixtures were lower than that of 2 in spite of higher polymer concentrations. These results apparently show the existence of interactions between 1 and $\mathbf{2}$.

Conformation analysis of $\mathbf{2}$ in this system is informative for discussion of the effects of the shape of the part- ner polyelectrolyte on the chain conformation. Several investigations have been reported on the conformation of polypeptides in ion complex formation between poly(Lglutamic acid) and poly(L-lysine). ${ }^{42}$ They form a $\beta$ pleated sheet structure with $1: 1$ stoichiometry at $\mathrm{pH} 4$ and 7 in a $0.01 \mathrm{~mol} \mathrm{~L}^{-1} \mathrm{NaF}$ aqueous solution, although poly(L-lysine) itself is in a random coil conformation under the same conditions and poly(L-glutamic acid) itself is in a random coil conformation at $\mathrm{pH} 7$ and an $\alpha$-helix conformation at $\mathrm{pH}$ 4. Poly(L-lysine) can be considered an analogue of PAMAM dendrimer because both repeating units have one amide, one amine, and four methylene groups. The CD spectra of the mixtures of 1 ( $G=$ $5.0)$ and $2\left(M_{w}, 1.5 \times 10^{4}\right)$ ([cation]/[anion] $=0.50$ and 2.0 ) in water indicate that 2 is in a random coil conformation at both charge ratios. The spherical shape and dense charge in internal and surface regions of the globule may make 2 form neither $\alpha$-helix nor $\beta$ sheet structure in water.

\section{CONCLUSION}

In this study the formation of ion complexes between PAMAM dendrimer $\mathrm{HCl}$ salt (1) (ethylenediamine core, $G=3.0$ and 5.0) and poly(L-glutamic acid) sodium salt (2) $\left(M_{w}, 1.3 \times 10^{4}, 1.5 \times 10^{4}\right.$, and $\left.8.9 \times 10^{4}\right)$ in water and phosphate buffers was confirmed by $\mathrm{pH}$, turbidity, viscosity, and CD measurements and electrophoresis analysis. One characteristic of this ion complex system is the water-soluble character, probably due to the globular shape and molecular structure of $\mathbf{1}$. 1 has cationic charges not only on the surface but also on internal skeleton, which is quite different from micelles and carboxylated PAMAM dendrimers having charges only on the surface. Therefore, PAMAM dendrimer $\mathrm{HCl}$ salt (1) can be regarded as a new class of polycations. Such dendritic polyelectrolytes are expected to perform novel functions, for example, ion complex formation containing 


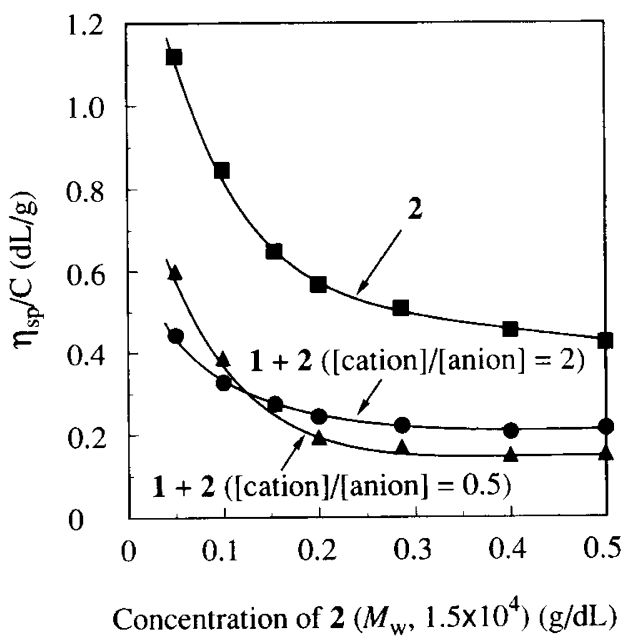

Figure 6. Dependence of the viscosity of mixtures of $1(G=5.0)$ and $2\left(M_{\mathrm{w}}, 1.5 \times 10^{4}\right)$ ([cation] / [anion] $=0,0.5$, and 2.0 ) on the concentration of 2 (expect 1 ). Temperature, $27^{\circ} \mathrm{C}$.

small molecules and inorganic nanoclusters. The $\mathrm{pH}$ responsive character owing to the components of a weak polyacid and a weak polybase suggests that this ion complex system is potentially applicable as $\mathrm{pH}$ responsive materials.

Acknowledgment. We thank Professor Norihiro Tsukagoshi and Dr. Masashi Kato (Nagoya University) for valuable suggestions in electrophoresis analysis. This work was partially supported by the Grant-in-Aid Encouragement of Young Scientists No.1986 from the Ministry of Education, Science, Sports and Culture of Japan. K. T. is a Research Fellow of the Japan Society for the Promotion of Science.

\section{REFERENCES}

1. D. A. Tomalia, A. M. Naylor, and W. A. Goddard III, Angew. Chem. Int. Ed. Engl ., 29, 138 (1990).

2. J. M. J. Fréchet, Science, 263, 1710 (1994).

3. G. R. Newkome and C. N. Moorefield, "Advances in Dendritic Macromolecules," JAI Press, Greenwich, 1994, Vol.1, pp 168.

4. D.-L. Jiang and T. Aida, Nature, 388, 454 (1997).

5. F. Zeng and S. C. Zimmerman, Chem. Rev., 97, 1681 (1997).

6. N. Tomioka, D. Takasu, T. Takahashi, and T. Aida, Angew. Chem. Int. Ed., 37, 1531 (1998).

7. Y. Li, P. L. Dubin, R. Spindler, and D. A. Tomalia, Macromolecules, 28, 8426 (1995).

8. H. Zang, P. L. Dubin, R. Spindler, and D. A. Tomalia, Ber. Bunsenges. Phys. Chem., 100, 923 (1996).

9. V. A. Kabanov, A. B. Zezin, V. B. Rogacheva, Z. G. Gulyaeva, M. F. Zansochova, J. G. H. Joosten, and J. Brackman, Macromolecules, 32, 1904 (1999).

10. E. Tsuchida and K. Abe, Adv. Polym. Sci., 45, 1 (1982).

11. E. Tsuchida, Y. Osada, and K. Sanada, J. Polym. Sci., Part A1, 10, 3397 (1972).

12. P. L. Dubin, S. S. Thé, L. M. Gan, and C. H. Chew, Macro- molecules, 23, 2500 (1990).

13. T. Sato, M. Kamachi, M. Mizusaki, K. Yoda, and Y. Morishima, Macromolecules, 31, 6871 (1998).

14. H. Tanzawa, Y. Mori, N. Harumiya, H. Miyama, M. Hori, N. Ohshima, and Y. Idezuki, Trans. Am. Soc. Artif. Intern. Organs, 19, 188 (1973).

15. F. Lim and A. M. Sun, Science, 210, 908 (1980).

16. C. Plank, K. Mechtler, F. C. Szoka, Jr., and E. Wagner, Hum. Gene Ther., 7, 1437 (1996).

17. S. Asayama, M. Nogawa, Y. Takei, T. Akaike, and A. Maruyama, Bioconjugate Chem ., 9, 476 (1998).

18. A. Harada and K. Kataoka, Science, 283, 65 (1999).

19. J. Haensler and F. C. Szoka, Jr., Bioconjugate Chem ., 4, 372 (1993).

20. J. F. Kukowska-Latallo, A. U. Bielinska, J. Johnson, R. Spindler, D. A. Tomalia, and J. R. Baker, Jr., Proc. Nat. Acad. Sci. USA., 93, 4897 (1996).

21. A. M. Naylor, W. A. Goddard III, G. E. Kiefer, and D. A. Tomalia, J. Am. Chem. Soc., 111, 2339 (1989).

22. G. R. Newkome, C. N. Moorefield, G. R. Baker, M. J. Saunders, and S. H. Grossman, Angew. Chem., Int. Ed. Engl., 30, 1178 (1991).

23. C. J. Hawker, K. L. Wooley, and J. M. J. Fréchet, J. Chem. Soc., Perkin Trans. 1, 21, 1287 (1993).

24. J. F. G. A. Jansen, E. M. M. de Brabander-van den Berg, and E. W. Meijer, Science, 266, 1226 (1994).

25. M. Zhao, L. Sun, and R. M. Crooks, J. Am. Chem. Soc., 120, 4877 (1998).

26. L. Balogh and D. A. Tomalia, J. Am. Chem. Soc., 120, 7355 (1998).

27. A. Archut, G. C. Azzellini, V. Balzani, L. D. Cola, and F. Vögtle, J. Am. Chem. Soc., 120, 12187 (1998).

28. G. Pistolis, A. Malliaris, D. Tsiourvas, and C. M. Paleos, Chem. Eur. J ., 5, 1440 (1999).

29. K. Tsutsumiuchi, K. Aoi, and M. Okada, Polym. J., 31, 935 (1999).

30. K. Aoi, K. Tsutsumiuchi, and M. Okada, Macromolecules, 27, 875 (1994).

31. K. Tsutsumiuchi, K. Aoi, and M. Okada, Macromol. Rapid Commun., 16, 749 (1995).

32. K. Aoi, K. Tsutsumiuchi, E. Aoki, and M. Okada, Macromolecules, 29, 4456 (1996).

33. K. Tsutsumiuchi, K. Aoi, and M. Okada, Macromolecules, 30, 4013 (1997).

34. K. Aoi, K. Tsutsumiuchi, A. Yamamoto, and M. Okada, Tetrahedron, 53, 15415 (1997).

35. M. Okada, K. Aoi, and K. Tsutsumiuchi, Proc. Japan Acad., 73, Ser. B, 205 (1997).

36. K. Aoi, K. Tsutsumiuchi, A. Yamamoto, and M. Okada, Macromol. Rapid Commun., 19, 5 (1998).

37. H. Hirabayashi, M. Nishikawa, and M. Hashida, Pharm. Res., 13, 880 (1996).

38. K. Kobayashi, E. Tawada, T. Akaike, and T. Usui, Biochim. Biophys. Acta, 1336, 117 (1997).

39. S. Kamiya and K. Kobayashi, Macromol. Chem. Phys., 199, 1589 (1998).

40. H. Kamitakahara, T. Suzuki, N. Nishigori, Y. Suzuki, O. Kanie, and C.-H. Wong, Angew. Chem. Int. Ed., 37, 1524 (1998).

41. D. A. Tomalia, H. Baker, J. Dewald, M. Hall, G. Kallos, S. Martin, J. Roeck, J. Ryder, and P. Smith, Polym. J., 17, 117 (1985).

42. A. Nakajima, K. Shinoda, T. Hayashi, and H. Sato, Polym. J., 7, 550 (1975). 